\title{
A numerical model for simulating thermal comfort prediction in public transportation buses
}

\author{
Youssef Riachi, Denis Clodic \\ Department of Energy and Processes, Mines-Paristech, Paris, France \\ Email address: \\ youssef.riachi@gmail.com (Y. Riachi), denis.clodic@mines-paristech.fr (D. Clodic)
}

To cite this article:

Youssef Riachi, Denis Clodic. A Numerical Model for Simulating Thermal Comfort Prediction in Public Transportation Buses. International Journal of Environmental Protection and Policy. Vol. 2, No. 1, 2014, pp. 1-8. doi: 10.11648/j.ijepp.20140201.11

\begin{abstract}
A numerical simulation model that predicts the thermal comfort in public transportation buses was developed. A precise approach based on the assembly of zonal and nodal models, coupled with CFD results obtained for stationary conditions, is used to simulate the thermal and air flow phenomena inside the passenger compartments. The model allows to determine the thermal (solar, passenger, and convective) loads of the bus and then to qualify the comfort level using the equivalent temperature. Simulations carried out show the influence of air distribution inside the bus on passenger's thermal comfort.
\end{abstract}

Keywords: Thermal Comfort, CFD, Zonal Model, Equivalent Temperature, Mannequin, Public Buses

\section{Introduction}

Comfort in public transportation buses, especially thermal comfort, is gaining importance in order to increase the public transport attractiveness. Thermal environment in a public transportation bus is different than that existing in buildings where the geometrical orientation is always fixed, the occupancy rate is relatively low, doors are not opened frequently and glazed area is reduced or curtained. The high occupancy rate in public buses requires large quantities of fresh air. The geometrical orientation as well as glazed surface determines the solar load that can be reduced by using special glazing or curtains.

Moreover, thermal environment in a bus is unlike that existing in SUVs, cars, trains or airplanes. In such cases, passengers are sited during a long travel relatively close to air diffusers. Moreover, the orientations as well as the air blown flow rate and temperature are adjustable.

Several studies were carried out in order to evaluate thermal comfort in SUVs. Fujita and Nakagawa developed a numerical method able to evaluate thermal environment in a vehicle [1]. Tanabe and Waseda evaluated thermal comfort in a vehicle in the presence of a reflective windshield [2]. Han and Huang have evaluated the thermal loads of a passenger car while indicating the local comfort level of its occupants [3].

Other studies were carried out for cars and trains. A study carried out by Eusébio Z.E. Conceiçao allows evaluating the thermal behaviour of a car by using the thermal response of the cabin and passengers [4]. Mann and Haigis simulated the circulation of air and thermal comfort in a suburban train [5]. In the literature, no investigators have dealt with thermal comfort in public city buses where the case is singular compared to aforementioned states.

This study presents a numerical model that allows evaluating the thermal dynamic behaviour of the cabin and its contents, and then to estimate the comfort level for passengers distribution in various locations and thus the human perception sensitivity to air flow distribution under realistic climatic conditions.

\section{Thermal Comfort Evaluation approach}

When measuring the thermal indoor climate, it is important to remember that a person does not only feel the room ambient temperature, but also the energy loss from his body. The interaction of several parameters like air temperature, nearby surface temperature, solar radiation and air velocity are crucial for the thermal sensation.

Thermal comfort is the condition of mind that expresses satisfaction with the thermal environment and is assessed by subjective evaluation [6]. Two conditions must be fulfilled to assure thermal comfort of a person in a given environment. 1) The actual combination of skin temperature and body's core temperature provides a sensation of thermal neutrality. 
2) The fulfilment of the body's energy balance: the heat produced by the metabolism should be equal to the amount of heat lost from the body. P.O. Fanger [7] derived a "Comfort equation" that describes the relationship between the measurable physical parameters and thermally neutral sensation as experienced by a person.

A simple but accurate approach for evaluating thermally comfortable environment is the "Equivalent Temperature $\left(\mathrm{T}_{\mathrm{eq}}\right)$ ". According to Holmer [8], the $\mathrm{T}_{\mathrm{eq}}$ is the most relevant scheme to measure thermal effects inside cabins. Empirical expressions of the equivalent temperature were developed by taking into account the diverse factors of influence [9]. The equivalent temperature is thus calculated using the appropriate thermal environment data (air temperature, mean radiant temperature, and air velocity) and the clothing's insulation, without the need for carrying out body energy balance. The expression proposed by Madsen is applicable for a metabolism $\mathrm{M}<100 \mathrm{~W} \mathrm{~m}^{-2}$ and is determined for two air velocity range:

$\mathrm{Va}<0.1 \mathrm{~m} \mathrm{~s}^{-1}$ :

$$
T_{e q}=0.5\left(T_{a}+\bar{T}_{r}\right)
$$

$$
\begin{aligned}
& \mathrm{Va}>0.1 \mathrm{~m} \mathrm{~s}^{-1}: \\
& T_{e q}=0.55 \times T_{a}+0.45 \times \bar{T}_{r}+\frac{0.24-0.75 \times \sqrt{V_{a}}}{1+I_{c l}}\left(36.5-T_{a}\right)
\end{aligned}
$$

The comfort zones are dressed in figure 1 for the whole human body as well as for its different segments. The comfortable zone is the one which varies from 16.5 to $22{ }^{\circ} \mathrm{C}$ related to the body segment considered. A person has a neutral comfort feeling if the equivalent temperature for the whole body varies from 22 to $24.5^{\circ} \mathrm{C}$.

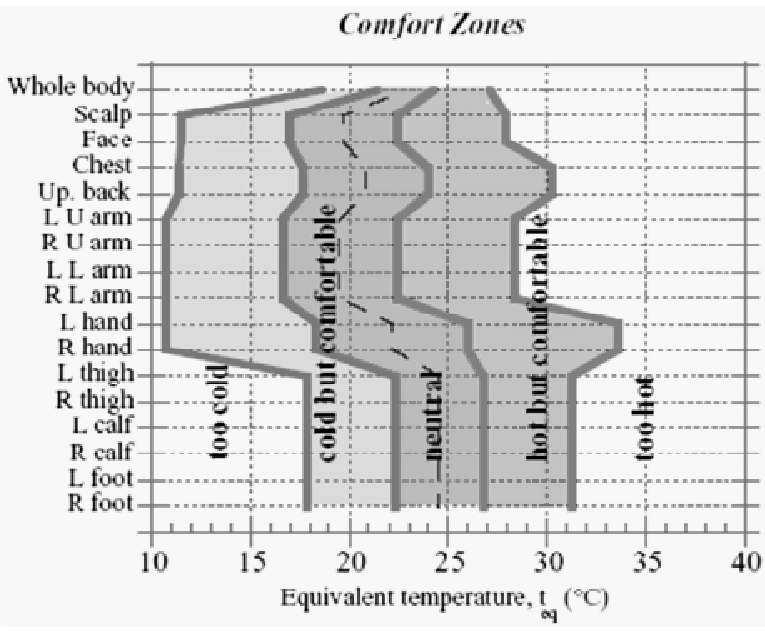

Figure 1. Thermal comfort for the whole human body as well as for the different segments [10]

According to the equivalent temperature approach determined for the whole body, the passenger thermal sensation will be as described in table 1 .
Table 1. Human thermal comfort level function of $T_{e q}[10]$

\begin{tabular}{ll}
\hline Equivalent temperature $\left(\mathbf{T}_{\text {eq }}\right)$ & Thermal comfort sensation \\
\hline $\mathrm{T}$ eq $<18.5^{\circ} \mathrm{C}$ & too cold and uncomfortable \\
$18.5^{\circ} \mathrm{C}<\mathrm{T}$ eq $<22{ }^{\circ} \mathrm{C}$ & cold but comfortable \\
$22{ }^{\circ} \mathrm{C}<\mathrm{T}$ eq $<24.5^{\circ} \mathrm{C}$ & neutral \\
$24.5{ }^{\circ} \mathrm{C}<\mathrm{T}$ eq $<27.5^{\circ} \mathrm{C}$ & hot but comfortable \\
$27.5^{\circ} \mathrm{C}<\mathrm{T}$ eq & too hot and uncomfortable \\
\hline
\end{tabular}

\section{Equivalent Temperature Sensitivity Analysis}

According to equations (1) \& (2), when air velocities lower than $0.1 \mathrm{~m} \mathrm{~s}^{-1}$, the equivalent temperature varies linearly with mean radiant temperature and ambient temperature with a half slope. In contrast, for air velocities higher than $0.1 \mathrm{~m} \mathrm{~s}^{-1}, \mathrm{~T}_{\mathrm{eq}}$ varies linearly with MRT but its variation to ambient temperature is related to air velocities and clothing insulation.

$\mathrm{Va}<0.1 \mathrm{~m} \mathrm{~s}^{-1}$ :

$$
\frac{\partial T_{e q}}{\partial T_{r}}=0.45
$$

And $\mathrm{Va}>0.1 \mathrm{~m} \mathrm{~s}^{-1}$ :

$$
\frac{\partial T_{e q}}{\partial T_{a}}=0.55-\frac{0.24-0.75 \sqrt{v_{a}}}{1+I_{c l}}
$$

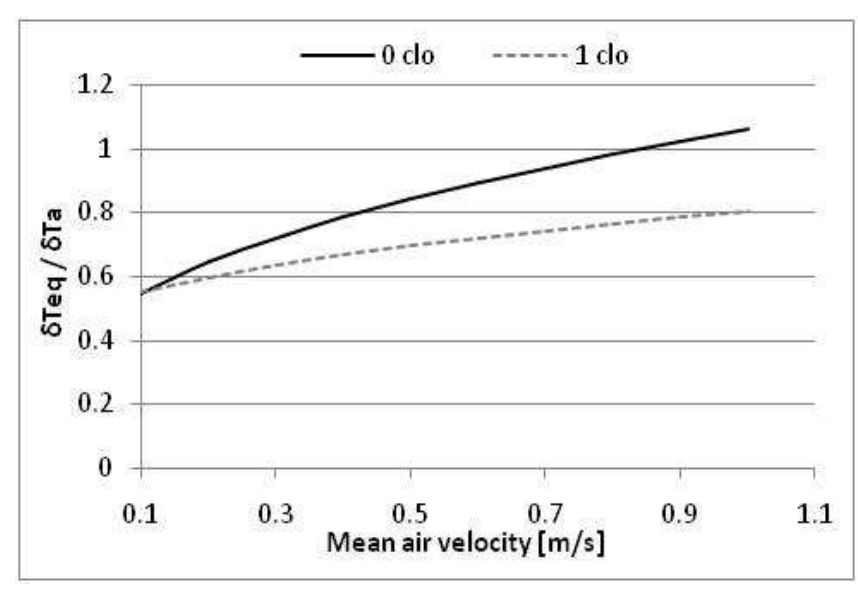

Figure 2. Equivalent Temperature sensitivity to air velocity variation

An MRT variation of $1 \mathrm{~K}$ implies constantly a $0.45 \mathrm{~K}$ variation of the $T_{\text {eq }}$ in the same direction. It is not the case for the ambient air temperature where its effect depends on the air velocity and on the passenger clothing. A high air velocity and a light passenger clothing imply a large variation of the differential $\delta$ Teq / $\delta$ Ta. Figure 2 addresses the effect the air velocity has on the equivalent temperature for a very light and well-dressed passenger. A high clothing insulation reduces the influence of air velocity on $\mathrm{T}_{\mathrm{eq}}$. 
Table 2. Insulation values of some garments [11]

\begin{tabular}{ll}
\hline Garments & Clothing insulation (clo) \\
\hline Cool socks & 0.03 \\
Warm socks & 0.04 \\
Short sleeved cool shirt & 0.2 \\
Long sleeved cool shirt & 0.28 \\
Long sleeved warm Pull-over & 0.37 \\
Cool trousers & 0.26 \\
Warm trousers & 0.44 \\
Shoes & 0.04 \\
\hline
\end{tabular}

The clothing insulation of a subject intervenes in its body energy balance since it constitutes a resistance to the heat and moisture transfer between the body and its environment. Clothing thermal insulation is generally expressed in clo which corresponds to an equivalent thermal resistance of about $0.155 \mathrm{~m}^{2} \mathrm{~K} \mathrm{~W}^{-1}$. In order to characterize the thermal insulation of clothing, static thermal mannequins are used. Table 2 shows some insulation values of individual garments. A person overall clothing insulation is determined by applying equation 5 :

$$
I_{c l}=0.75 \sum I_{c l, i}+0.08
$$

\section{Outline of the Numerical Simulation Model}

A precise approach based on the assembly of zonal and nodal models, coupled with CFD (computational fluid dynamics) simulation outputs obtained for stationary conditions, is used to simulate the thermal and air flow phenomena inside the passenger compartment. The numerical model allows first to evaluate the thermal dynamic behaviour of the cabin and its contents and then to estimate the comfort level for passengers positioned in various locations, under realistic climatic conditions.

\subsection{Thermal Mannequin Use for Teq Evaluation}

In order to evaluate thermal comfort by numerical approach using the equivalent temperature, it is necessary to integrate thermal mannequins in the model. Mannequins are introduced in sitting and standing positions (cf Figure 3). The use of mannequins allows determining the mean air velocity, the solar energy received as well as the mean radiant temperature on each one of them, and thus the perceived equivalent temperature.

The mannequins are introduced into the CFD, radiative and thermal models. Mean air velocities are determined on the whole body of the mannequin. The solar energy received by each mannequin and various bodies constituting the internal and external parts of the cabin are calculated using software MODRAY ${ }^{\circledR}$ [12]. MODRAY ${ }^{\circledR}$ allows also calculating the mutual exchanges in infra-red between various bodies. The energy balance will be then solved for the different zones and components of the cabin using software THERMETTE® [13].

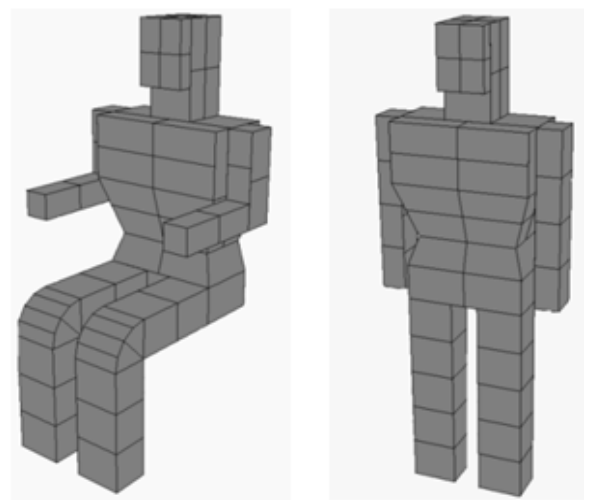

Figure 3. Mannequins in sitting and standing positions

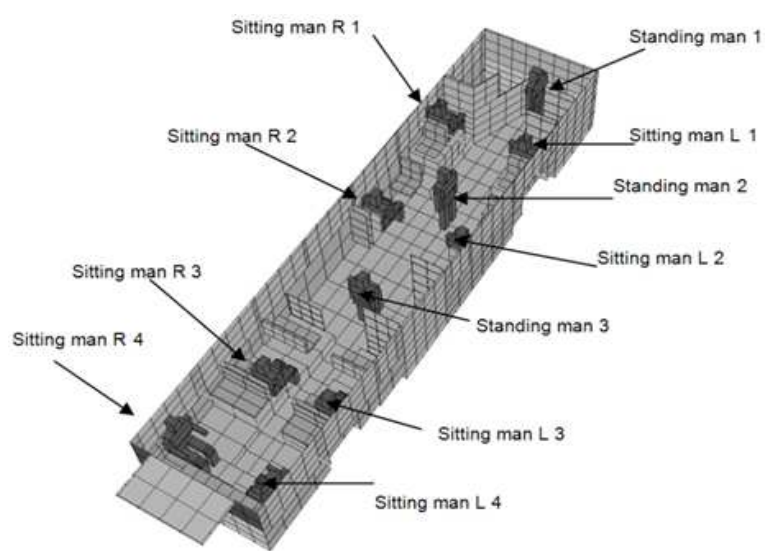

Figure 4. Mannequin in sitting and standing positions inside the bus cabin

Eleven mannequins are introduced and positioned inside the bus cabin (cf. Figure 4). Three of them are placed in upright position; the first one is placed near to the driver compartment, the second in the front passageway and the third one in the central platform. Eight other mannequins are placed in sitting position on the left and right seats in a way to cover several possible cases.

Once the ambient temperature, the mean radiant temperature and the air velocity are determined, the equivalent temperature is calculated for the different mannequins taking into consideration a suitable physical activity and clothing insulation. A passenger taking the bus is considered to have respectively an activity of 1 Met when he is sitting and 1.2 Met when he is standing up. The clothing insulation is assumed to be 0.5 clo corresponding to summer time.

\subsection{Cabin Zonal Representation}

A bus passenger receives various kinds of heat transfer effects, a direct touch (seat, standing bars and hot glazing), infrared radiant heat from other components, solar heat through the glass, and air temperature inside the cabin. These parameters have to be taken into account in order to determine the equivalent temperature for the whole passenger's body. It should be mentioned that this study 
does not consider the effect of conduction on thermal comfort.

As the cabin shows a longitudinal vertical symmetry, the problem could have been treated symmetrically by taking just one side (right or left). However, the solar load contribution in the mean radiant temperature is crucial and thus affects strongly the equivalent temperature. For this reason thermal mannequins are installed on both right and left sides. The longitudinal distribution of the mannequins will take into account the possible heterogeneity of a non-homogeneous air distribution inside the cabin. A detailed flow study for several bus air distribution systems will be studied and presented.

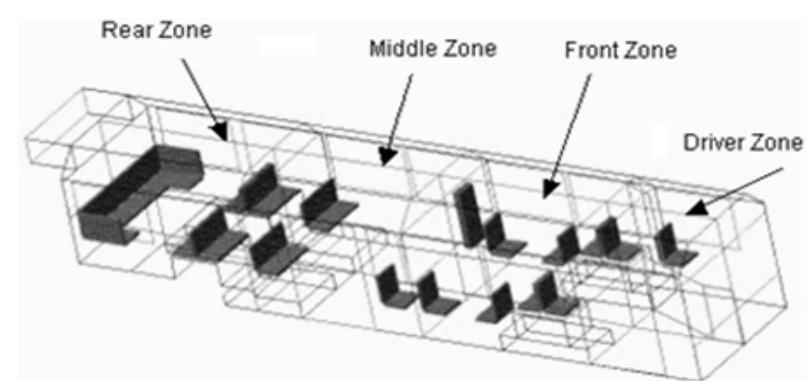

Figure 5. Bus cabin zonal divisions

The bus cabin is divided into 4 different zones: rear, middle, front and driver zones. Each of the sited zones is then split into 6 parts: left and right for three different levels (top, mid and floor). So in total, the bus cabin is divided into 24 zones each of it considered at uniform temperature (cf. Figure 5).

A fine representation of the air velocity fields inside the cabin as well as on the different internal surfaces and mannequin faces is imperative in order to be introduced in the $\mathrm{T}_{\mathrm{eq}}$ equation. Moreover the geometry of the bus cabin has to be described precisely in order to determine the thermal load (solar radiation, heat conductive, radiative and convective). However, from a thermal dynamics point of view, it is necessary to represent the dynamic behaviours; thermal modelling must be simpler and integrate the cartography of the flows coming from modelling CFD. These results are integrated in a broad approach presented hereafter.

\subsection{Model Assembly Approach}

The vehicle thermal behaviour model is based not only on energy balance equations for the air inside each sub compartment but takes into account different slices of vehicle main bodies, windows glasses and interiors bodies. It considers the convective (forced), conductive (in the main bodies divided in several slices), irradiative (shortwave and long wave radiation outside and inside the vehicle) and air flow transfer (inside the compartments) phenomena.

The zonal model uncouples heat transfer problem from flow problem (no temperature-dependent properties or buoyancy forces). Based on this assumption the velocity fields and the flows between zones are determined using
CFD numerical analysis software (Fluent Inc.) regardless of boundaries and volumes temperatures. Velocity fields and flows inter-zones are then introduced as entries to be set in

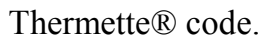

The numerical methodology used is a typical approach known as a software assembly, using several simulation codes independent from each other. Each software allows the calculation of the parameters intervening to answer a precise purpose:

- The radiative exchanges and solar loads are carried out by Modray ${ }^{\circledR}$ software,

- The calculation of the air flows between zones and the velocity profiles are determined using Fluent,

- The coupling of heat (conductive, convective, radiative) and mass transfers, are finally carried out by the thermal software solver Thermette ${ }^{\circledR}$.

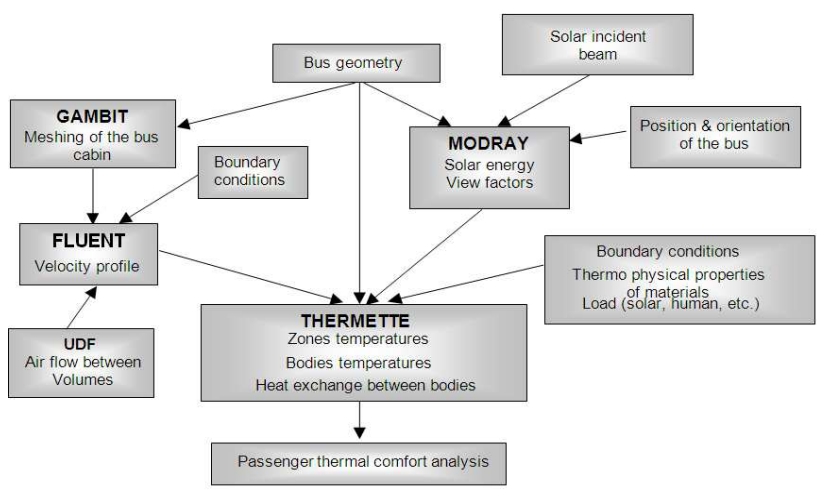

Figure 6. Model structure flowchart for thermal comfort analysis

The air flow distribution between volumes constitutes a zonal approach coupled with a nodal resolution in order to characterize the thermal fields. Nodes represent at the same time, the solid elements inside the cabin as well as air volumes, considered at uniform temperature. The heat transfers within the vehicle depend on the cabin geometry and its components, the boundary conditions, and air temperature and velocities. The boundary conditions take into account incident solar radiation on each external and internal wall, the surrounding air temperature and the mean bus displacement speed.

\section{Solar and Radiation Analysis Using Modray ${ }^{\circledR}$}

As mentioned before, the solar direct and diffuse radiation incidents on the internal and external surfaces of the bus, as well as the radiative heat exchange between internal bodies are determined using Modray ${ }^{\circledR}$ [12].

$$
F_{i j}=\frac{1}{\pi S_{i}} \int_{S_{i}} \int_{S_{j}} \frac{\cos \theta_{i} \cos \theta_{j}}{r_{i j}^{2}} d S_{i} d S_{j}
$$

The diffuse radiation between gray surfaces, in each enclosure, is determined by radiosity equations system and 
view factors. The view factors and then the exchange factors between the internal surfaces are calculated by computing the sum on discrete geometry in the form of plane facets (cf. Equation 6).

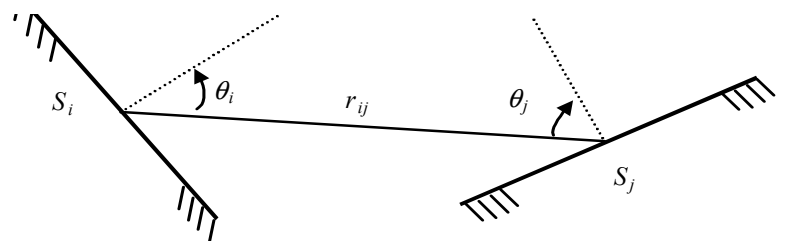

Figure 7. View factor between two surfaces

In case of non-black surfaces, it is necessary to consider the emissivity. A so called coatings method is used to calculate the exchange factors between gray bodies. The absorbed solar heat by external and internal bodies of the bus cabin is calculated by determining direct as well as diffused radiation. The radiant temperature (Eq.7) perceived by the mannequins takes account of incident solar radiation and the diffuse radiation between the mannequin body and the surrounding 192 surfaces. The mannequin body is discredited in 35 facets [12].

$$
\bar{T}_{r}=\sqrt[4]{\frac{\sum_{i=1}^{n} f_{i p} \cdot T_{i}^{4}+\frac{\phi}{\sigma}}{A_{p} \cdot \varepsilon_{p}}}
$$

The bus cabin consists of several branches and volumes.
The solid walls and elements are represented by branches (1D element) while respecting the various layers. The internal air volume of the bus is divided into 24 sub volumes (0D element) considered at uniform temperature. The so called "supply air" volumes are those who exchange heat with the cold battery and allow determining the air supply temperature function of the cooling capacity and the supply air flow rates.

This simplified representation of the bus cabin implies certainly several geometrical and physical assumptions to be considered:

- Temperature of the solid bodies varies in one dimension (1D element)

- Temperature of air volumes is uniform (0D element)

- Thermo physical properties of the components which constitute the cabin are supposed to be independent of the temperature.

- Air thermo physical properties vary with the temperature and correspond to those of dry air.

- Air does not intervene in radiation (transparent to radiation)

- Radiative exchanges occur according to three spectral bandwidths: visible, short and long infra-reds.

- Reflectivity and emissivity of surfaces are isotropic

The general equation governing heat transfer inside and at the boundary limits of $1 \mathrm{D}$ branch is described in the following equation (Eq.8) [13].

\section{Thermette ${ }^{\circledR}$ Representation}

$$
\frac{\partial}{\partial u}\left(\lambda \cdot S(u) \cdot \frac{\partial T}{\partial u}\right)-\dot{m} \cdot c \cdot \frac{\partial T}{\partial u}-h \cdot p(u) \cdot\left(T-T_{f i n}\right)+q_{v} \cdot(u) \cdot S(u)=\rho \cdot c_{p} \cdot S(u) \cdot \frac{\partial T}{\partial t}
$$

The term on the right represents the internal energy increase rate. On the left, the first term represents the conduction inside the $1 \mathrm{D}$ branch, the second term represents the of enthalpy transfer in case of a mass flow. The third term represents a possible side wall heat exchange (fin type) with an ambient temperature $\mathrm{T}_{\text {fin }}$.

The last term on the right is the source in case of internal power generation inside the branch with a volume density qv. Equation 8 is discretized in space by volume or finite element (references), as selected by the user. This allows having a partial differential equation with boundary conditions in a system of differential-algebraic equations of the form:

$$
A_{b} T+U_{b}=C_{b} \dot{T}_{b}
$$

$\mathrm{T}$ is the temperature vector of the system and $\mathrm{Tb}$ is the branch temperature. Matrix $\mathrm{Ab}$ represents internal interactions (conduction, and exchange rates), both within the branch as well as between the branch and the remaining components. $\mathrm{Cb}$ represents the self-matrix in the branch. Vector $\mathrm{Ub}$ represents the action of external loads.

In case of a volume ( $0 \mathrm{D}$ element), the energy balance can be written as an ordinary differential equation:

$$
A_{v} T+U_{v}=\rho \cdot c \frac{d T_{v}}{d t}
$$

In equation 10, the right-hand term represents the increase rate of internal energy of the volume. The left term represents the sum of the energy gained by the volume. This energy gain may come from internal heat exchange (first term) or external loads (second term). The assembly of components equations for the whole network can be written in a differential-algebraic form of equation 9 but with broad matrices $\mathrm{A}$ and $\mathrm{C}$ and broad vectors $\mathrm{T}$ and $\mathrm{U}$.

\section{Model Validation in Unsteady State Condition}

Subsequent to the model assembly, an experimental validation step have to precede the evaluation of the inside cabin comfort level. The available experimental results for model validation are tests on a rolling test bench carried inside a climatic chamber at the UTAC.

The goal of these tests is to study the thermal behavior inside the cabin and to value the overconsumption caused by 
the use of the AC system for system type B. The solar and passengers loads are substituted by radiative electrical resistance of $7500 \mathrm{~W}$. The ambient condition temperature inside the climatic chamber is fixed at $30^{\circ} \mathrm{C}$.

Starting from the same initial conditions, the simulation is carried out for 1800 seconds (the test time length). Temperature profile evolutions out coming from simulation are plotted and compared to experimental measurements. Results for two sub compartment levels are shown in Figure 8. The dashed line temperatures are those of the model and the continuous lines are those measured.

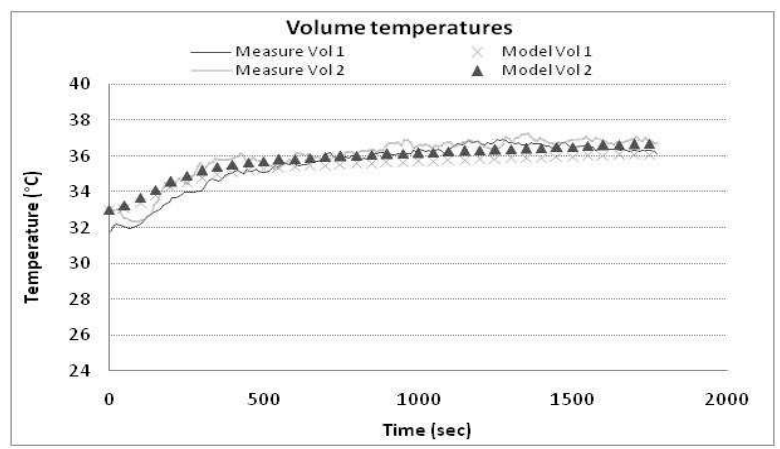

Figure 8. Simulation results compared to experimental data

A high grade of concordance between the experimental measurements and the simulation results is found. Temperature trends for major elements and sub compartments are well respected; the average temperature gap between the model and the tests does not exceed $1 \mathrm{~K}$.

\section{Analysis of the Cabin Air Flow Distribution}

On the basis of the model presented above, three ventilation types are simulated and the comfort level is assessed for each of them for the different mannequin positions. The difference between the three system types is the air flow rate, supply and return. The corresponding air flow rates are 2400,1400 and $1500 \mathrm{~m}^{-1} \mathrm{~h}^{-1}$, respectively, for Type A, B and C.

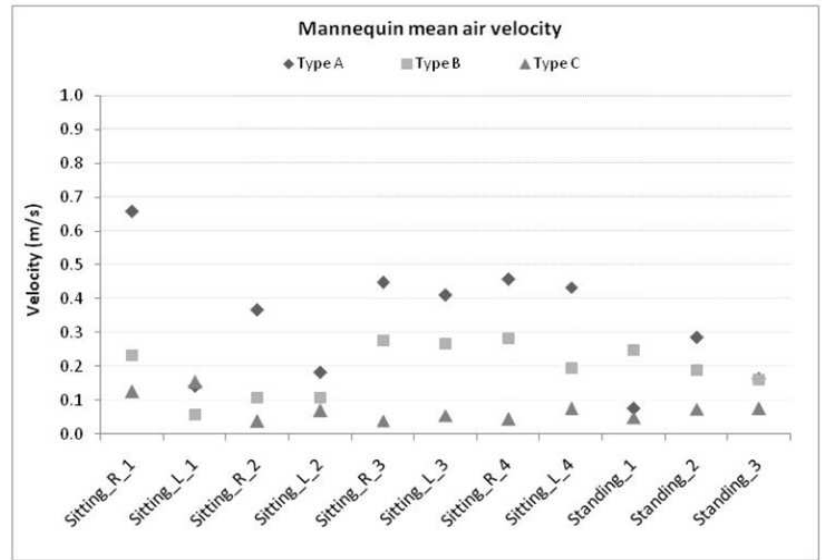

Figure 9. Mean air velocity on the mannequins for the three systems
For system A, air is supplied at four locations directly at the passengers head level and return is pumped at the ceiling level. For system B, only fresh air is supplied at 5 locations in the middle of the cabin. Whilst for system $\mathrm{C}$, fresh air is supplied parallel to glazing at the cabin length (the distribution is not uniform).

Mannequins are introduced in CFD models representing the three system air distribution. Boundary conditions are applied concordant with the real state of each system. Air velocities are then calculated inside the cabin confinement and at the boundary surfaces. As a result air velocities could be calculated on each part of the mannequin's body as a well as averaged on each of them.

The air velocity difference between the three systems is considerable. The gaps are important between the front and the rear of the cabin for both systems Type A and B. For system $\mathrm{C}$, air velocities are very weak at the rear and the middle of the cabin (cf. Figure 9).

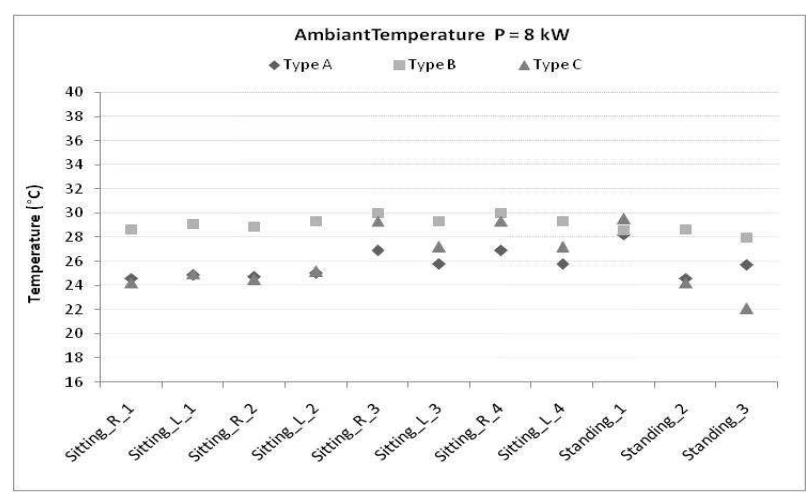

Figure 10. Ambient temperature at mannequin level for the three systems

Given that the identical cooling capacities are applied for the three systems, the ambient temperature that surrounds each mannequin will only be dependent on the air return source. In case of system B, supply air is coming from outside at $30{ }^{\circ} \mathrm{C}$. It is evident that even at equal cooling capacities; the ambient temperature will be higher as there is no air recirculation. The effect of air distribution on ambient temperature is visualized when comparing case A to case $\mathrm{C}$ where a poor air distribution (system $\mathrm{C}$ ) at the rear leads to higher ambient temperatures (cf. Figure 10).

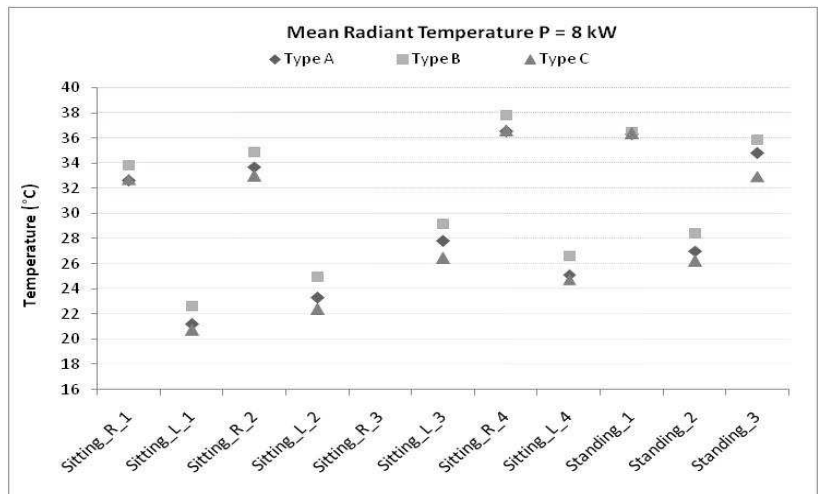

Figure 11. MRT perceived by mannequins for the three systems 
The mean radiant temperature (MRT) is affected by the solar flux received by the mannequin as well as by the mutual exchanges between the mannequin and various internal surfaces of the bus cabin. The solar energy received by the cabin and by the mannequins is equal in the three cases. The cooling capacity is also considered equal thus the difference in the MRT perceived by a mannequin for the three cases is then dependant only on the air distribution.

The influence of the solar energy received by a mannequin is very significant and affects the MRT considerably, the variation can reach $14{ }^{\circ} \mathrm{C}$ between two mannequins at right and left (Sitting_R_1 and Sitting_L_1), which revealing the importance of an appropriate glazing choice (cf. figure 11). The difference between two mannequins feelings located at the same side, (right or left), is mainly due to air and cooling capacity distribution.

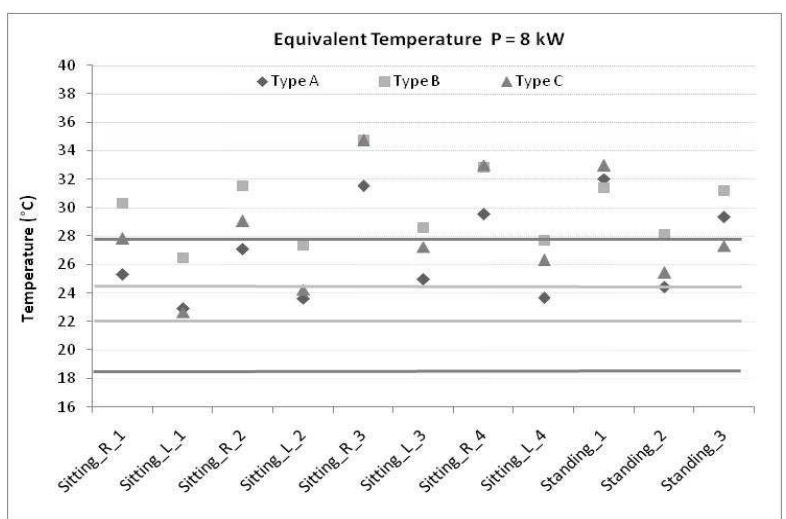

Figure 12. Equivalent temperature perceived by mannequins for the three systems

The equivalent temperature comparison on several mannequins located at various places for the same cooling capacity allows revealing the various criteria influencing thermal comfort (cf. Figure 12). Moreover, this comparison illustrates the defects an air distribution system had. Thus, a cooling capacity even sufficient and greater than the thermal loads is not evidently efficient and does not meet the goals unless if it is uniformly spread inside the cabin.

For this reason system a shows 4 mannequins over 10 are in comfort conditions while 2 are for system C. In case of system $\mathrm{B}$ none of the mannequin is feeling comfortable.

\section{Conclusion}

In this paper, a new methodology for assessing the thermal comfort inside a public transportation bus is presented. Based on the coupling of several approaches zonal, nodal and CFD, software like Thermette ${ }^{\circledR}$, Modray ${ }^{\circledR}$ and Fluent are coupled to predict the temperature evolution inside the bus cabin.

The Equivalent temperature approach is used to assess the passenger comfort at different locations inside the bus cabin. Fictive thermal mannequins are considered in the model where air velocities, ambient air temperature, mean radiant temperature and finally equivalent temperature are determined on each mannequin.

The equivalent temperature notion allows showing the diversity of the thermal situations in the bus, as well as the different comfort level found.

The differences in equivalent temperatures perceived by mannequin at different locations inside the cabin prove the zonal aspect of the problem and the necessity to promote for a solution that considers this aspect.

\section{Nomenclature}

\begin{tabular}{|c|c|c|}
\hline A & surface area & $\mathrm{m}^{2}$ \\
\hline $\mathrm{Cp}$ & heat capacity & $\mathrm{J} \mathrm{kg}^{-1} \mathrm{~K}^{-1}$ \\
\hline fcl & Clothing factor & \\
\hline $\mathrm{Fcl}$ & $\begin{array}{l}\text { heat transfer reduction factor due to } \\
\text { clothing }\end{array}$ & \\
\hline Fij & view factor & \\
\hline fij & Transfer factor & \\
\hline $\mathrm{h}$ & enthalpy & $\mathrm{kJ} \mathrm{kg}^{-1}$ \\
\hline h, hc & convective heat exchange coef & $\mathrm{W} \mathrm{m} \mathrm{m}^{-2} \cdot \mathrm{K}^{-1}$ \\
\hline $\mathrm{hr}$ & irradiative heat exchange coef & $\mathrm{W} \mathrm{m}{ }^{-2} \cdot \mathrm{K}^{-1}$ \\
\hline Icl & Clothing insulation & $\mathrm{K} \mathrm{W}^{-1}$ \\
\hline $\mathrm{m}$ & masse & $\mathrm{kg}$ \\
\hline $\mathrm{P}$ & thermal load & $\mathrm{W}$ \\
\hline Q & heat exchange & $\mathrm{W}$ \\
\hline $\mathrm{r}$ & distance & $\mathrm{m}$ \\
\hline $\mathrm{S}$ & exchange surface & $\mathrm{m}^{2}$ \\
\hline $\mathrm{T}$ & temperature & $\mathrm{K}$ or ${ }^{\circ} \mathrm{C}$ \\
\hline $\mathrm{t}$ & time & $\mathrm{s}$ \\
\hline $\mathrm{u}$ & velocity component & $\mathrm{m} \mathrm{s}^{-1}$ \\
\hline $\mathrm{V}, \mathrm{Va}$ & velocity component & $\mathrm{m} \mathrm{s}^{-1}$ \\
\hline
\end{tabular}

\section{Subscripts}

$\begin{array}{ll}\Delta & \text { variation } \\ \mathrm{a} & \text { ambient } \\ \mathrm{c} & \text { convective } \\ \mathrm{cl} & \text { clothing } \\ \mathrm{conv} & \text { convection } \\ \mathrm{eq} & \text { equivalent } \\ \mathrm{ij} & \text { mutual exchange between } \mathrm{i} \text { et } \mathrm{j} \\ \mathrm{p} & \text { person } \\ \mathrm{r}, \text { rad,ray } & \text { radiant } \\ \mathrm{s} & \text { solar } \\ \mathrm{s} & \text { surface } \\ \mathrm{V} & \text { volumetric }\end{array}$

\section{Greek Symbols}

$\begin{array}{lll}\alpha & \text { Absorption factor } & \\ \varepsilon & \text { Emissivity } & \\ \phi & \text { Flux, solar load } & \mathrm{W} \\ \lambda & \text { Conductivity } & \mathrm{W} /(\mathrm{m} . \mathrm{K}) \\ \mu & \text { Viscosity } & \mathrm{Pa} . \mathrm{s} \\ \rho & \text { Density } & \mathrm{Kg} \mathrm{m} \\ \sigma & \text { Stefan - Boltzmann constant } & \mathrm{W}\left(\mathrm{m}^{-2} \cdot \mathrm{K}^{-4}\right)\end{array}$




\section{Abbreviations}

$\begin{array}{ll}\text { CFD } & \text { Computational Fluid Dynamics } \\ \text { L } & \text { Left } \\ \text { M } & \text { Middle } \\ \text { MRT } & \text { Mean Radiant Temperature } \\ \text { R } & \text { Right } \\ \text { SUV } & \text { Sports utility vehicle } \\ \text { TC } & \text { Thermal comfort }\end{array}$

\section{References}

[1] Nakagawa H., Fujita A.,Kanemaru J., Ozeki Y., 'Numerical simulation method to predict the thermal environment inside a car cabin" JSAE Review 22.

[2] Tanabe Schin-ichi Waseda, "Numerical prediction of thermal comfort in a vehicle with solar reflection glass", 3-4-1 Okubo, Shinjyuku-ku, Tokyo 169-8555, Japan 2002.

[3] Han T., Huang L., and Kelly S.," 'Virtual Thermal Comfort Engineering" SAE Paper, SAE 2001 World Congress Detroit Michigan March 2001, 2001-01-0588.

[4] Eusébio Z.E. Conceiçao, 'Integral simulation of passengers and vehicles thermal response : Evaluation of thermal comfort and air quality"- University of Algavre Portugal 2003.

[5] Mann M. and Haigis M., 'Numerical Investigation of the
Ventilation and Thermal Comfort in a Commuter Train", arsenal research, Business Area Transport Technologies Vienna Austria 2001.

[6] ANSI/ASHRAE Standard 55-2013, Thermal Environmental Conditions for Human Occupancy.

[7] Fanger P O (1970). Thermal Comfort: Analysis and applications in environmental engineering. McGraw-Hill.

[8] Holmer I., Parsons K., Bohm H., ' 'Equivalent temperatures in vehicules - conclusions and recommendations for standards", Cabli seminar .1999.

[9] Madsen T.L., Olesen O.W., Kristensen N.K., "'Comparison between operative and equivalent temperature under typical indoor conditions", ASHRAE transactions, 1984, part 3, pp $1077-1090$.

[10] Nilsson H. and Holmér I., "'Comfort diagrams for improved evaluation of indoor climate", The Climate Group, The National Institute for Working Life, Sweden, SE-171 84 Solna, Sweden, Proceedings of the Fourth International Meeting on Thermal Manikins, EMPA Switzerland, 27-28 Sept 2001.

[11] Pasons K.C., "Human thermal environments", 1993 Taylor \& Francis, London.

[12] http://www.dep.mines-paristech.fr/Valorisation/Ressources/ MODRAY/.

[13] http://www.dep.mines-paristech.fr/Valorisation/Ressources/ THERMETTE/. 